\title{
Performance Advantage of Wintering Cattle in California's Sacramento Valley
}

\author{
By Larry Forero, James Oltjen, Steve Blank, and Norman Taylor
}

\section{On the Ground}

- In this six year study fall calving cows grazing annual grassland in the Sacramento Valley of California weaned heavier calves than their cohorts fed hay in the mountains.

- The heavier weaned calves wintered on annual grasslands continued to be heavier than their cohorts wintered on hay in the mountains through the yearling phase.

- Winter grazing annual grasslands was economically favorable when compared to feeding hay in the mountains.

- The timing and amount of precipitation influence annual grassland forage production tremendously. There may be years when cattle fed hay in the mountains perform better than their cohorts grazing annual grassland.

Keywords: annual rangeland, beef cattle, ranch economics, winter pasture.

Rangelands 36(5):25-30

doi: 10.2111/RANGELANDS-D-14-00025.1

(C) 2014 The Society for Range Management

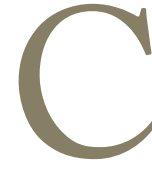

alifornia's diverse rangelands include forested, great basin, desert, coastal chaparral, and annual range types. Each of these range types requires livestock management unique to their ecology. The proximity of the state to Mexico and Hawaii has resulted in cattle from both places being shipped to California grasslands. Many ranches in the mountainous areas of California, southern Oregon, and western Nevada ship cattle to the California's valley and foothill annual grasslands for the winter. The mild Mediterranean climate and winter forage production is thought to provide cheaper input costs and improved livestock production. Livestock producers have compared the economic consideration of feeding cattle in the mountains over the winter to shipping cattle to the annual grassland and have found a financial advantage to wintering cattle on California's valley and foothill annual grasslands. Mountain ranches rely upon private meadows and irrigated pastures as well as public land for the summer. Many mountain ranches make hay during the summer months and feed that hay to their cattle during the winter. Reducing the amount of hay required to sustain livestock provides different opportunities for that forage resource. We could not find a study that evaluated the performance (weaning weights) associated with these production systems, which prompted us to initiate this trial. In this paper we address both the performance and economics of these two wintering scenarios.

\section{Materials and Methods}

The cooperating ranch operates on deeded irrigated land, leased land, and USFS grazing permits. The operator typically weans calves in the late spring and then holds the calves over the summer and sells as yearlings in the fall. Figure 1 shows the location of the mountain ranch and the leased annual grassland pasture. The elevations of the home ranch in the mountains (control) and annual grassland ranch in the Sacramento Valley are approximately 3,700 feet and 400 feet, respectively.

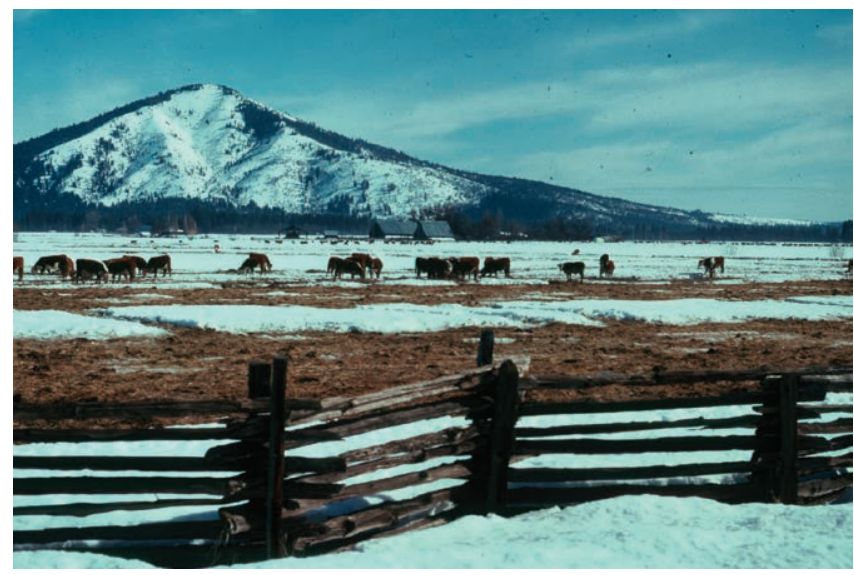

Cows and calves fed hay during the winter in the mountains of northeastern California. 


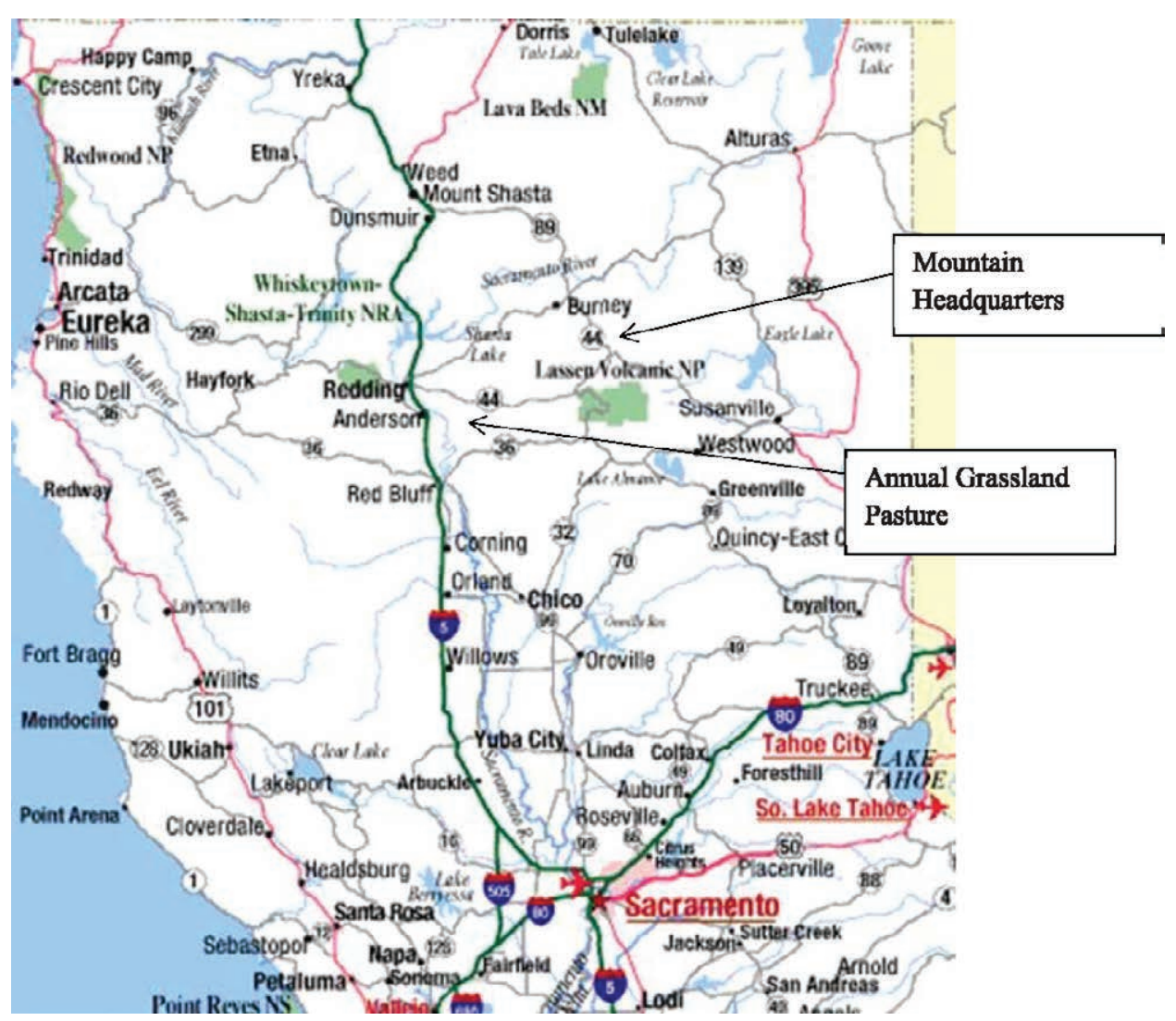

Figure 1. Location of mountain ranch (control) and valley ranch (annual grassland treatment).

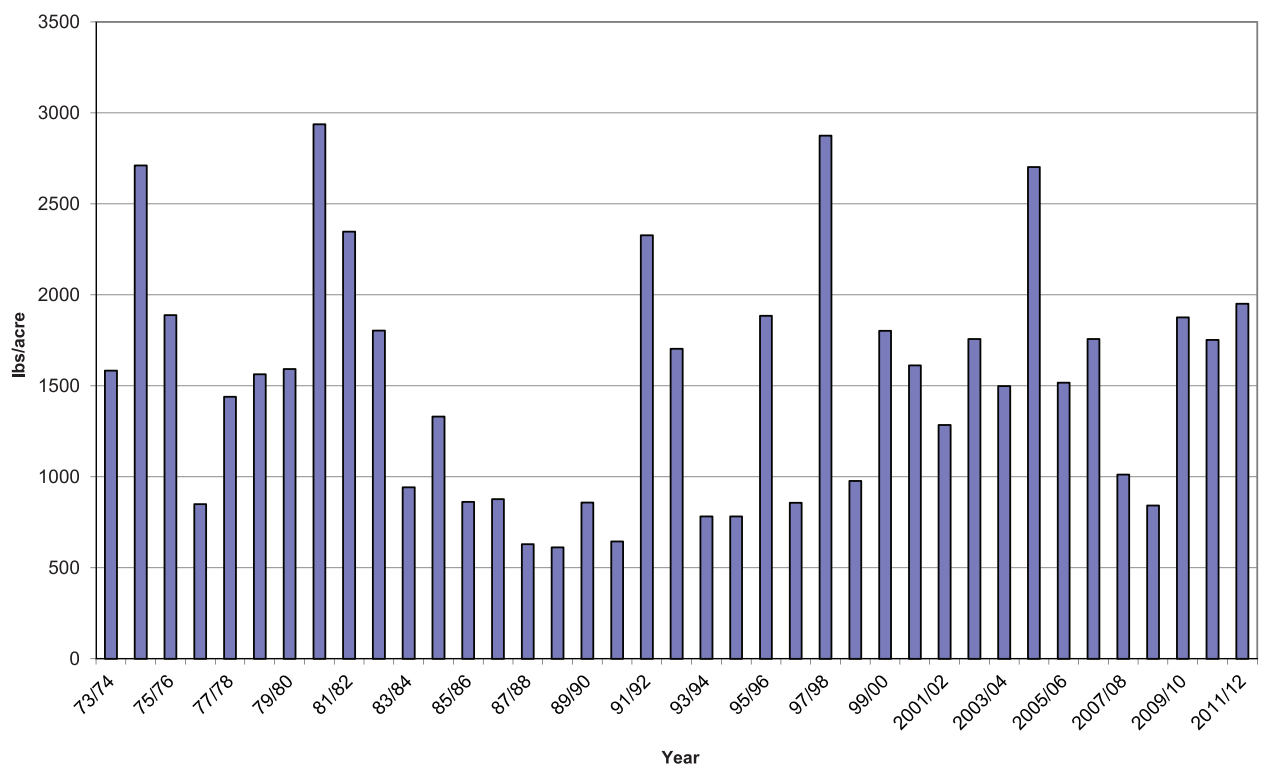

Figure 2. Dry matter forage production in pounds/acre, Redding, California.

Due to the variability in hay and livestock markets, as well as weather and its subsequent influence on forage production, this study was conducted over six years beginning in 2005. Figure 2 shows the variability of rangeland production on a site near the annual grassland pasture in the Sacramento Valley. ${ }^{1}$
In each of the six years of the trial, we randomly assigned 60 head of fall calving cows to each area, after stratifying by cow age and sex of the calves each of the six years of the trial. Control cattle remained in the mountains of northeastern California and were fed grass hay and alfalfa throughout 


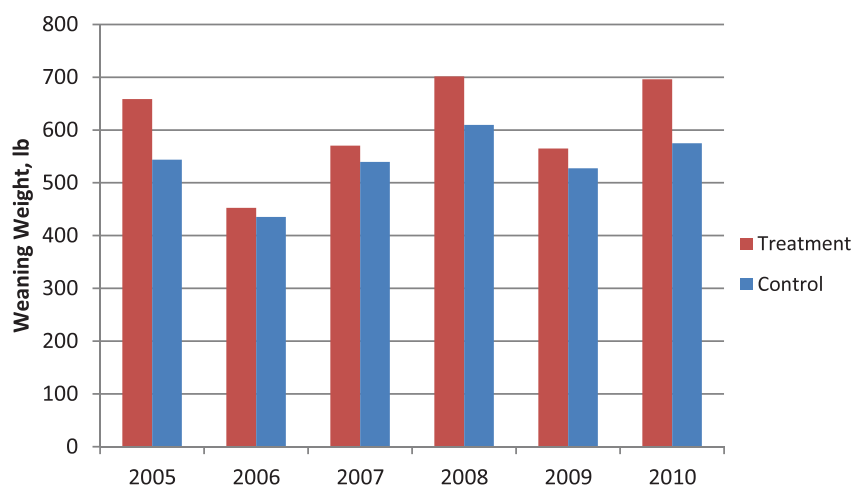

Figure 3. Valley (treatment) and mountain (control) weaning weights by year.

the winter. Approximately 2.5 tons of hay was fed to each cow and calf in the mountain group over the winter feeding period. Treatment cattle were shipped to annual grasslands in the northern Sacramento Valley and wintered on a leased ranch. The annual grassland was stocked at about 10 acres per cow/calf pair for the season. At the end of the season (typically late May), cattle were shipped back to the mountains, and the calves from both groups were weaned and weighed individually. Cattle were individually weighed as yearlings in the fall of the year. All cash cost data associated with the management of both groups were considered. Capital expenses (fences, corrals, etc.) associated with the valley pasture were amortized across the study period. Labor and equipment costs associated with feeding the mountain group were not considered.

We analyzed individual weight data using SAS GLM with sex, treatment, and year and all two-way interactions. Heifer and steer weaning weights were pooled within treatment (Fig. 3), which were not statistically different in each year of the study.

\section{Results and Discussion}

When we pooled the six years of data, the average treatment animal wintered in the valley was more than 60 pounds heavier than the average control animal wintered in the mountains (607 pounds for the average valley calf vs. 539 pounds for the average mountain calf $[P<0.001])$. When heifer and steer yearling weights were pooled and considered by treatment, a similar trend was noted (Fig. 4), with control and treatment weights not statistically different in some years. When we pooled the data across years, the average treatment cattle wintered in the valley were 50 pounds heavier than the

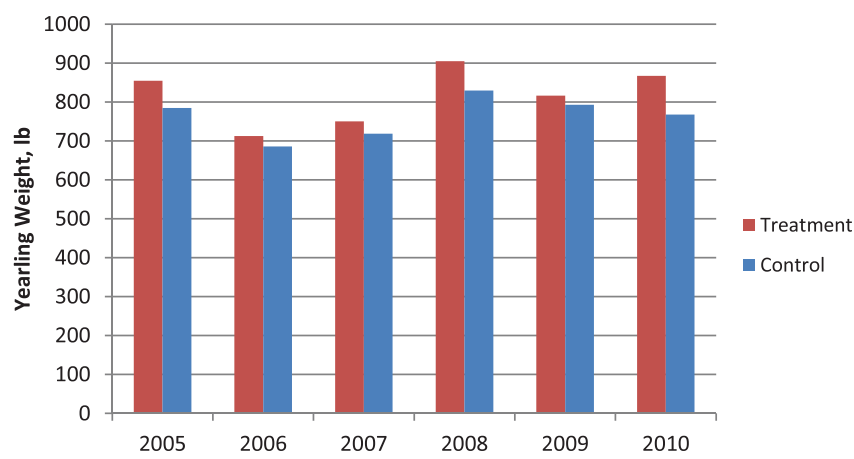

Figure 4. Valley (treatment) and mountain (control) yearling weights by year.

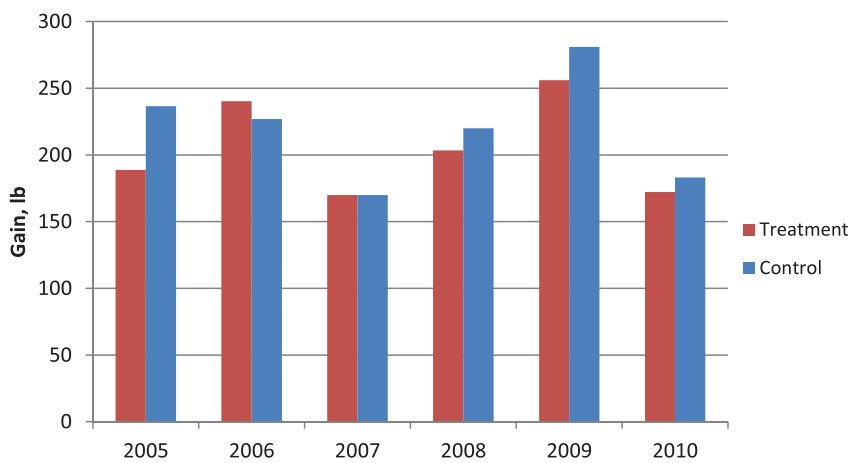

Figure 5. Valley (treatment) and mountain (control) cattle summer gains by year.

control cattle wintered in the mountains (818 pounds for the average valley calves vs. 763 pounds for the average mountain calves $[P<0.05])$. At weaning, both groups were turned out on grass together. Although the mountain steers gained slightly more total pounds across the 121-day period, the valley cattle were still significantly heavier at the end of trial. The valley heifers gained slightly more than the mountain heifers through the yearling phase (Fig. 5).

\section{Economics}

The economic comparison only considers the costs that are only associated with their respective assignment (treatment or control). We did not include production costs similar for both groups (e.g., summer pasture, vaccination). The major cost associated with the mountain cattle was the cost of hay. The hay was valued based upon local market prices ${ }^{2}$ listed in Table 1.

Costs associated with the valley cattle included pasture rent, infrastructure costs, freight, and travel associated with checking the cattle (Table 2). Pasture rent was indexed based

Table 1. Cost of alfalfa hay in Shasta County, California, US dollars per ton ${ }^{2}$

\begin{tabular}{|l|l|l|l|l|l|l|}
\hline & 2005 & 2006 & 2007 & 2008 & 2009 & 2010 \\
\hline Alfalfa hay & $\$ 115$ & $\$ 127$ & $\$ 138$ & $\$ 146$ & $\$ 177$ & $\$ 111$ \\
\hline
\end{tabular}


Table 2. Annual cost per cow of winter grazing in the Sacramento Valley

\begin{tabular}{|l|c|c|c|c|c|c|}
\hline & $\mathbf{2 0 0 5}$ & $\mathbf{2 0 0 6}$ & $\mathbf{2 0 0 7}$ & $\mathbf{2 0 0 8}$ & $\mathbf{2 0 0 9}$ & $\mathbf{2 0 1 0}$ \\
\hline Winter pasture & $\$ 106$ & $\$ 102$ & $\$ 94$ & $\$ 98$ & $\$ 95$ & $\$ 105$ \\
\hline Freight & $\$ 26$ & $\$ 24$ & $\$ 30$ & $\$ 32$ & $\$ 36$ & $\$ 30$ \\
\hline Infrastructure & $\$ 43$ & $\$ 43$ & $\$ 43$ & $\$ 43$ & $\$ 43$ & $\$ 43$ \\
\hline Travel & $\$ 282$ & $\$ 25$ & $\$ 28$ & $\$ 29$ & $\$ 31$ & $\$ 29$ \\
\hline Total & $\$ 202$ & $\$ 194$ & $\$ 195$ & $\$ 202$ & $\$ 205$ & $\$ 207$ \\
\hline
\end{tabular}

upon the value of weaned calves at Shasta Livestock Auction Yard with $\$ 100 /$ cow for the season set as the base rate. To calculate this, we divided each year's value of weaned calves by a ten-year rolling average value of weaned calves and multiplied by $\$ 100$. Infrastructure costs (fence constriction and corrals) were based upon actual material cost and amortized across the six years of the study. The freight rate varied annually. Travel cost was determined using IRS mileage rate and 1,764 miles per year (average of two trips per month to check cattle). Table 2 shows the per cow annual costs associated

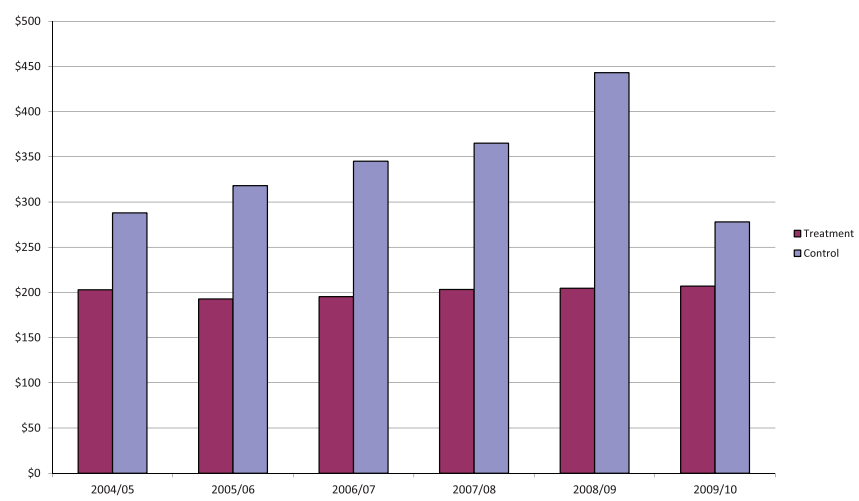

Figure 6. Annual cost by treatment on a per cow basis.

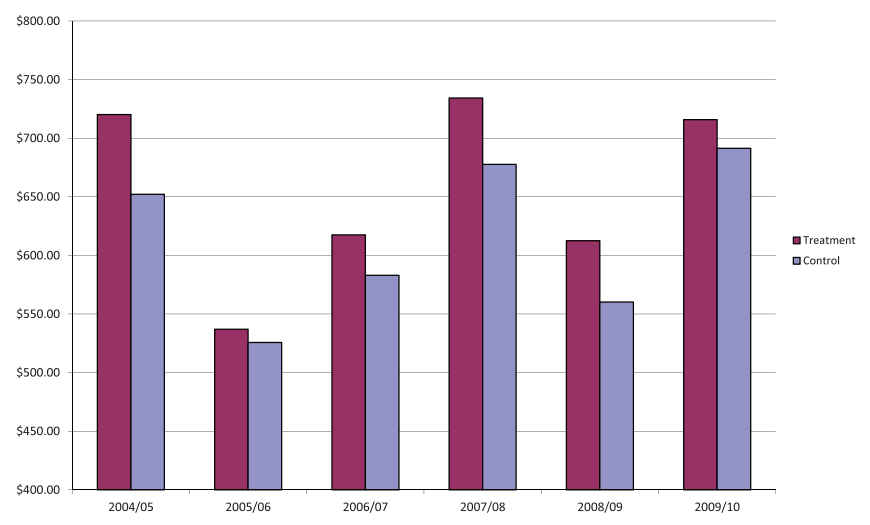

Figure 7. Per head value of weaned steers by treatment. with valley cattle. Annual costs on a per cow basis for both groups are presented in Figure 6.

\section{Economic Return}

To estimate the market cost value of the weaned calves and yearlings, we used the market report from Shasta Livestock Auction Yard. ${ }^{3}$ We used the market report from the second sale in June for the weaned calves and the market report from the second sale in October for the yearlings. The middle of the price range by weight class was used for each. Figures 7

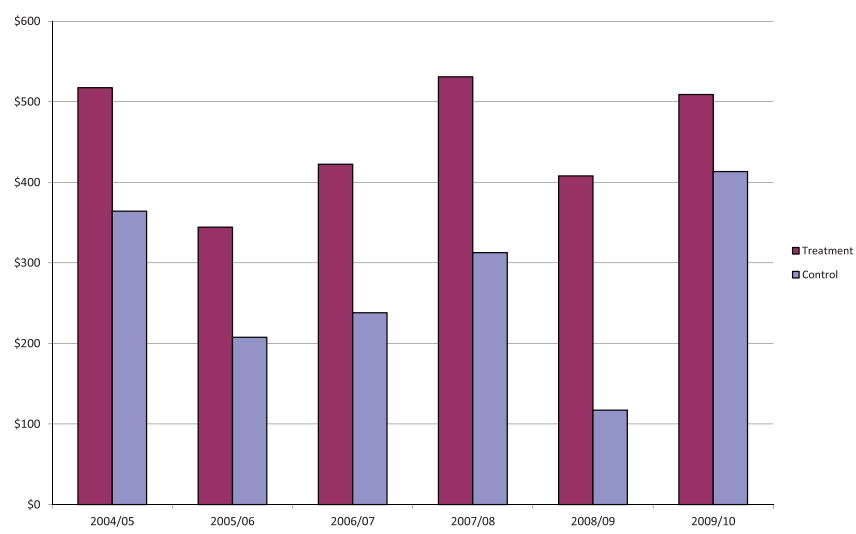

Figure 8. Return per weaned steer after respective costs are subtracted.

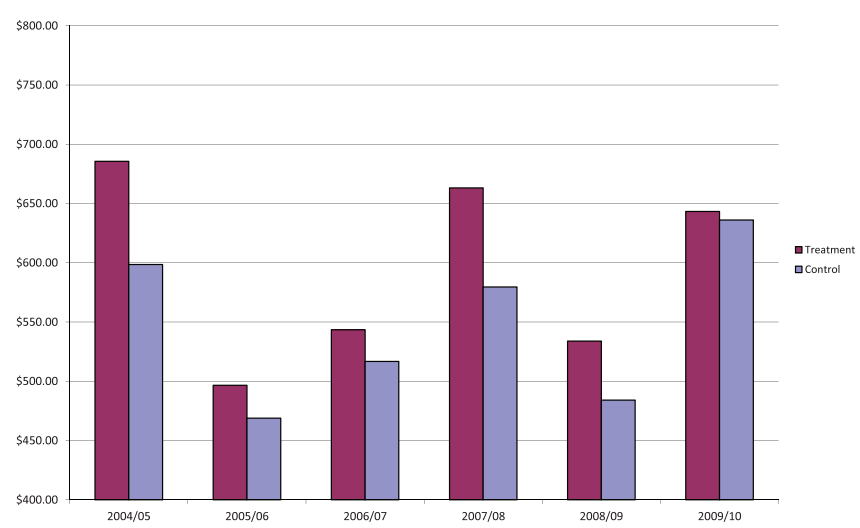

Figure 9. Per head value of weaned heifers by treatment. 


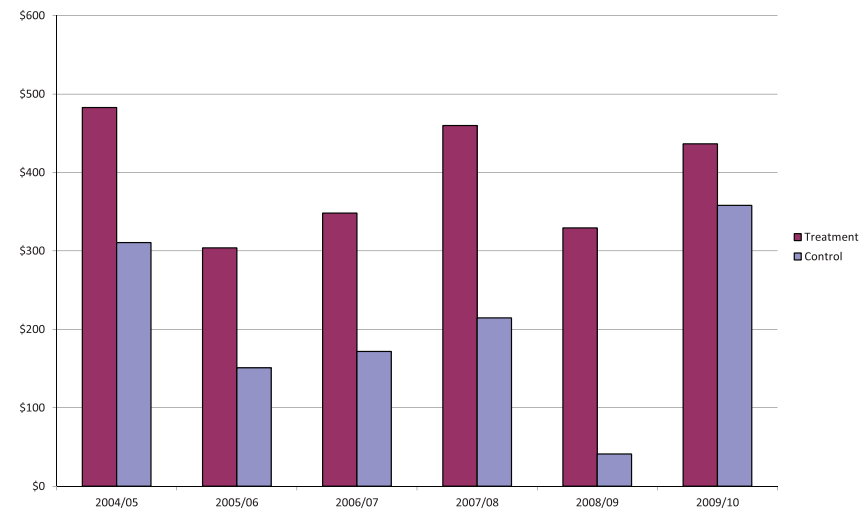

Figure 10. Return per heifer after respective costs are subtacted.

and 8 show the per head value of weaned steers and heifers by treatment. When reviewing these figures, it is important to recall the inverse price differential between lighter cattle and heavier cattle. Due to the market price differential between steers and heifers it is necessary to consider them separately.

The two major factors influencing the economics of wintering cattle on annual grassland are the higher weaning weights and the high cost of feeding hay in the mountains. Higher weaning weights and the high relative cost of hay both contributed to a significant economic advantage of utilizing valley annual grasslands for winter forage needs. Figures 9 and 10 show estimates of returns for both groups by sex.

\section{Conclusions}

Weaning weights of treatment cattle wintered in the valley were significantly heavier than control mountain cattle over the six years of the study, although there were years they were not significantly different. Yearling weights of valley cattle were significantly heavier than mountain cattle, indicating the performance advantage is retained through the yearling

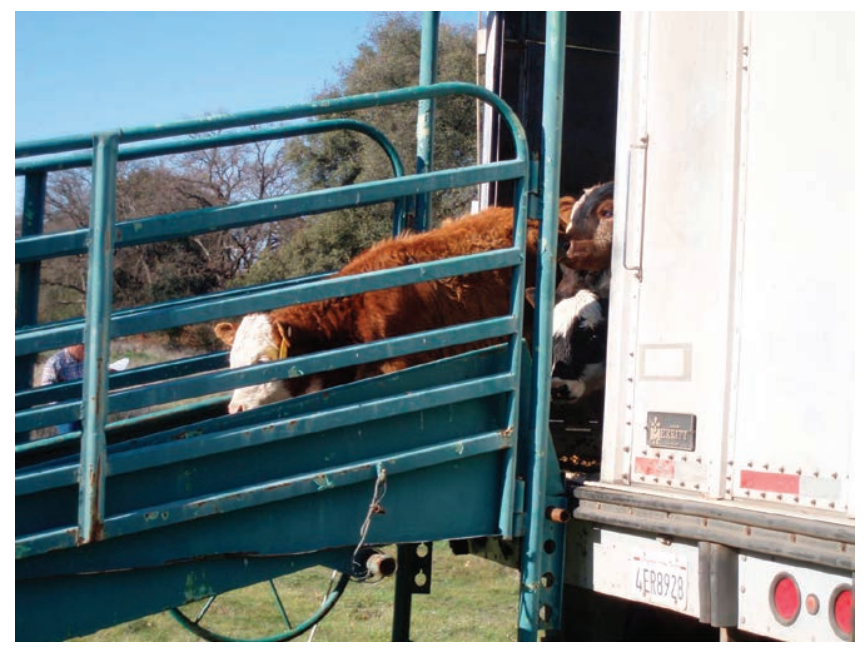

Unloading cattle. at the onset of the winter grazing season in the Sacramento Valley.

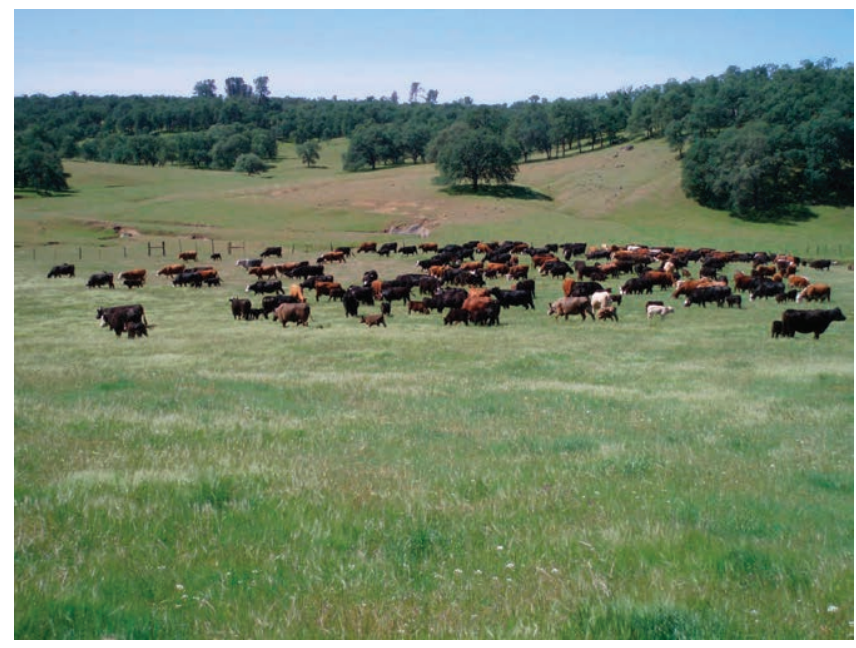

Cows and calves grazing annual grassland in the foothills of northern California.

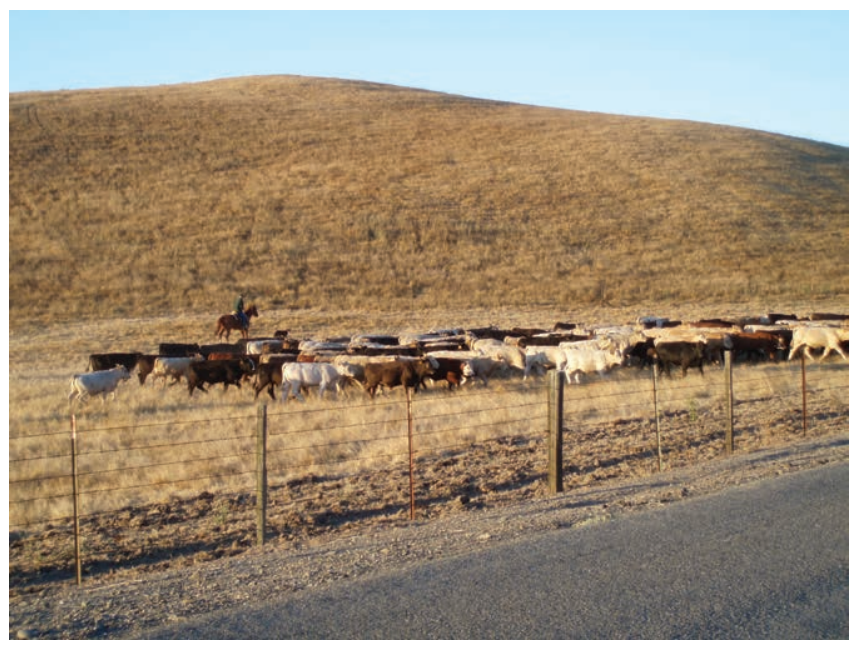

Seven-hundred-pound weaned steers driven to corrals for shipping from California annual rangelands.

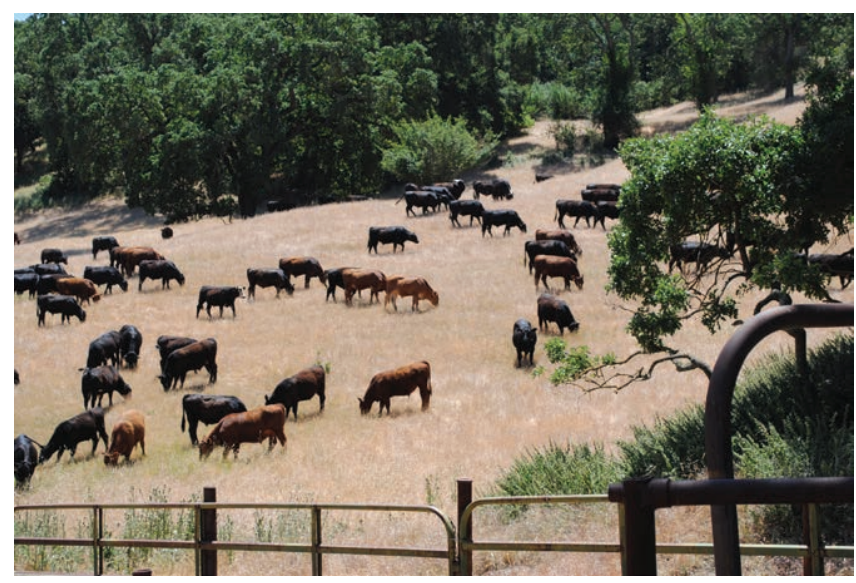

Nine-hundred-pound yearlings at the end of the grazing season on annual rangelands. 


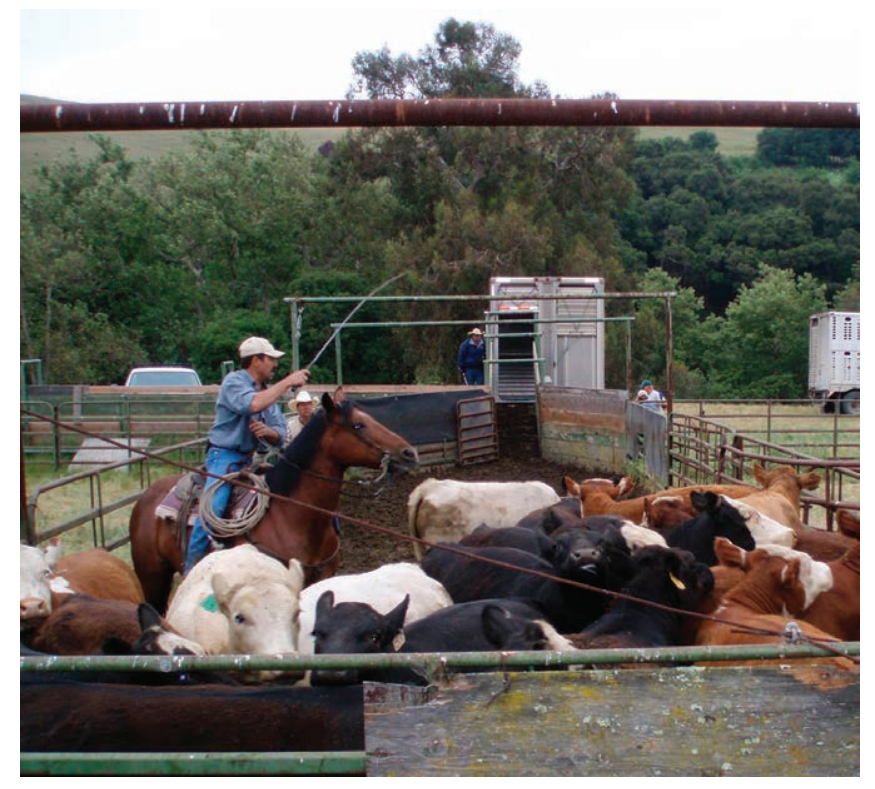

Alfonso Casillas loading steers at the end of the winter grazing season, Meyers Ranch, Union City, California.

phase; the compensatory gain advantage through the yearling phase for calves wintered in the mountains was small. The livestock market price and cost of hay influence the financial return associated with both strategies. In years when hay is priced high and rainfall is favorable, wintering cattle in the
Sacramento Valley generally makes economic sense. The improvement in weaning and yearling weights coupled with the reduction in production costs make wintering in the valley an attractive option.

\section{References}

1. Forero, L., And G. A. Nader. 2012. 2011/12 Northern California winter pasture experience varies. Northern California Ranch Update 4(2). Available at: http://ceshasta.ucanr.edu/newsletters/ Northern_California_Ranch_Update44036.pdf. Accessed July 2014.

2. Shasta County Agriculture Commissioners Crop Reports. Available at: http://www.co.shasta.ca.us/docs/Ag/crop-reports/ shasta2005.pdf?sfvrsn=0. Accessed 2010.

3. Shasta Livestock Auction Yard Market Reports. Available at: http://www.shastalivestock.com/shastareports.htm. Accessed 2010.

Authors are Livestock Farm Advisor, University of California Cooperative Extension, Redding, CA 96002, USA, lcforero@ ucanr.edu (Forero); Animal Management Systems Specialist, University of California, Cooperative Extension, Davis, CA 95616, USA (Oltjen); Dept Head and Professor, Agricultural and Applied Economics, Virginia Tech, Blacksburg, Virginia 24060, USA (Blank); and Owner, Wilcox Ranch, Hat Creek, CA 96040, USA (Taylor). 